CFD Letters

CFI Letters

\title{
Effect of Channel Arrangement on the Thermal Hydraulic Performance of Multilayer Microchannel Arrays
}

\author{
Natrah Kamaruzaman ${ }^{1,}$, Mohd Farhan Wisley ${ }^{1}$, Ummikalsom Abidin ${ }^{1}$, Mohsin Mohd Sies ${ }^{2}$, Mohd \\ Ridhwan Mohd Ruslan ${ }^{3}$ \\ 1 Department of Thermofluid, School of Mechanical Engineering, Faculty of Engineering, Universiti Teknologi Malaysia, 81310 Skudai, Johor, \\ Malaysia \\ 2 Department of Nuclear Engineering, School of Chemical Engineering, Faculty of Engineering, Universiti Teknologi Malaysia, 81310 Skudai, Johor, \\ Malaysia \\ 3 Malaysian-Japan International Institute of Technology, Universiti Teknologi Malaysia, 54100 Kuala Lumpur, Wilayah Persekutuan Kuala Lumpur, \\ Malaysia
}

\section{ARTICLE INFO}

Article history:

Received 20 June 2020

Received in revised form 19 August 2020

Accepted 24 August 2020

Available online 30 August 2020

Keywords:

Multilayer microchannel; heat transfer; thermal

\section{ABSTRACT}

\begin{abstract}
Thermal hydraulic performance of microchannel device is affected mainly by its geometrical parameter. The purpose of this study is to investigate the effect of multilayer microchannel arrangement to the thermal hydraulic performance of microchannel arrays. Numerical analysis was conducted to simulate three different microchannel arrangements by varying mass flow rate and heat flux imposed on the microchannel device. The simulation model is a simplified version which consists of eight microchannels in a single row and contains four layers for model one while model two has an arrangement of eight-seven-eight-seven microchannels in four layers and model three has an arrangement of seven-eight-seven-eight microchannels in four layers. The boundary condition that was set for heat flux ranged between $200 \mathrm{~W} / \mathrm{cm}^{2}$ to $1000 \mathrm{~W} / \mathrm{cm}^{2}$ while mass flow rate that flow into the device was varied between 20 $\mathrm{kg} / \mathrm{h}$ to $80 \mathrm{~kg} / \mathrm{h}$. From the simulation result, it is shown that certain arrangement of microchannel in multilayer channels contribute to the enhancement of heat transfer and at the same time reducing the pressure drop of the system.
\end{abstract}

Copyright @ 2020 PENERBIT AKADEMIA BARU - All rights reserved

\section{Introduction}

Nowadays microchannel cooling devices have become a cooling solution especially for portable and miniature devices with high heat generation. Till now, the research on microchannel devices are still focusing on heat transfer performance as the main objective but in the same time, pressure drop is another main issue to be solved where both parameters are contradicting to each other [1]. As the heat transfer performance increases, there will be high pressure drop which needs additional pumping system to overcome. Researchers aim to remove the additional pumping system because

\footnotetext{
* Corresponding author.

E-mail address: natrah@mail.fkm.utm.my (Natrah Kamaruzaman)
} 
the microchannel cooling devices are getting complex and consume more energy in terms of electricity and space. There are several approaches and modifications towards microchannel cooling devices to attain better outcome for both high heat transfer performance and low pressure drop [25].

The modification taken by researchers involves the geometry of the microchannel in terms of dimensions in height, width and length of the channel where these parameters may contribute to the heat transfer performance and pressure drop [6-8]. Researchers also discover some factors that contribute to high heat transfer with a low-pressure drop by varying the design of MCHS such as the length of the channel, type of flow, types of coolant used and the stacking or known as multilayer microchannel [9-12]. The advantages of multilayer microchannel heat sink are better heat transfer performance, small and compact size. However, the efficiency of multilayer microchannel still depends on the geometry (height, length, and width), types of coolant and operating condition such flow rate and inlet temperature $[12,13]$. Therefore, the objective of this study is to investigate the effect of different multilayer arrangement on the thermal hydraulic performance of microchannel device. This study is specific on short microchannel that is less than $0.5 \mathrm{~mm}$ or flow with developing profile. The results of this study might be applied to design a heat sink device that satisfies both heat transfer and pressure drop needs in industry.

\section{Methodology}

A simulation study has been performed to study the effect of microchannel arrangement on thermal hydraulic performance of multilayer channel.

\subsection{Simulation Model}

Three different microchannel arrangements are modelled and simulated using commercial CFD software. The total layer selection is selected based on the study done by Kamaruzaman et al., [1]. All models have microchannels with a height of 100 micrometer, length of 200 micrometer and width of 800 micrometer. The model used is simplified model which represent by one single row of microchannel instead of eight rows of microchannel in actual scale device [3].

Figure 1 shows the arrangement configurations for each model. All three models consist of four layers. Model one consists of total 32 microchannels where each layer is comprised of 8 microchannels. While model two consist of 30 microchannels with the configuration of eight-seveneight-seven microchannels in each layer. As for Model 3, the number of microchannels is similar as model two but the configuration is set as seven-eight-seven-eight microchannels for each layer.

\subsection{Boundary Condition and Solver Selection}

Water is chosen as the coolant and copper as material of the device. At the inlet, a mass flow boundary condition with inlet temperature of $27^{\circ} \mathrm{C}$ is set. The mass flow rate applied is ranged between $20 \mathrm{~kg} / \mathrm{h}$ to $80 \mathrm{~kg} / \mathrm{h}$. At the outlet the boundary condition of pressure outlet is specified. The value is set as atmospheric pressure. Heat flux boundary condition is set at the heating surface with a range between 200 to $1000 \mathrm{~W} / \mathrm{cm}^{2}$. Other wall is as symmetry based on actual devices. Figure 2 shows the example of boundary condition in Model 1. The other model also applied the same boundary conditions.

A commercial software is used to solve the mass, momentum, and energy equations to determine the velocity and thermal profile for this problem. Based on the assumptions made previously, 
pressure-based solver was selected to solve the pressure equation to achieve the constraint of mass conservation in the velocity field. This pressure equation was derived such that the corrected velocity field fulfilled the continuity equation. Further, solving the problem requires adaptation of the segregation solution method under the pressure-based solver. With this method, the governing equations were solved sequentially.

\subsection{Mesh Independent Test}

Grid independence has been tested on $\mathrm{M} 1$ to $\mathrm{M} 3$ which varies in term of numbers of nodes. The fine meshing size is selected at microchannel, inlet and outlet of water where this area is the focus to be analyzed. The number of nodes for each model can be refer from the Table 1. M1 to M3 undergo adapted region process to ensure the result obtain is more accurate because adapted region is tuned to make the meshing become finer. The number of nodes increase after the adapted region process undergoes as shown as in table. $\mathrm{M} 3$ is consider as grid independence value because the variation with $\mathrm{M} 1$ is $1.9 \%$ in term of temperature difference and $2.74 \%$ in term of pressure drop. The M1 contains half of the number of nodes which contains by M3. Thus, it is assuming that the M3 has achieve grid independence value. The results are shown in Figure 3.

Table 1

The summary of the number of nodes for each model

\begin{tabular}{llll}
\hline Parameter & M1 & M2 & M3 \\
\hline Total nodes & 99854 & 141198 & 220108 \\
Total nodes (after adapt region) & 447442 & 654054 & 1080308 \\
\hline
\end{tabular}

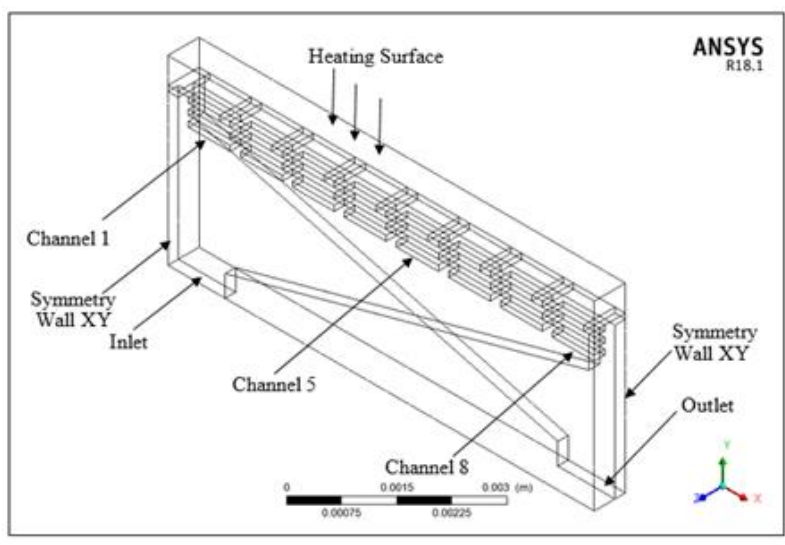

Sample of 3D Model

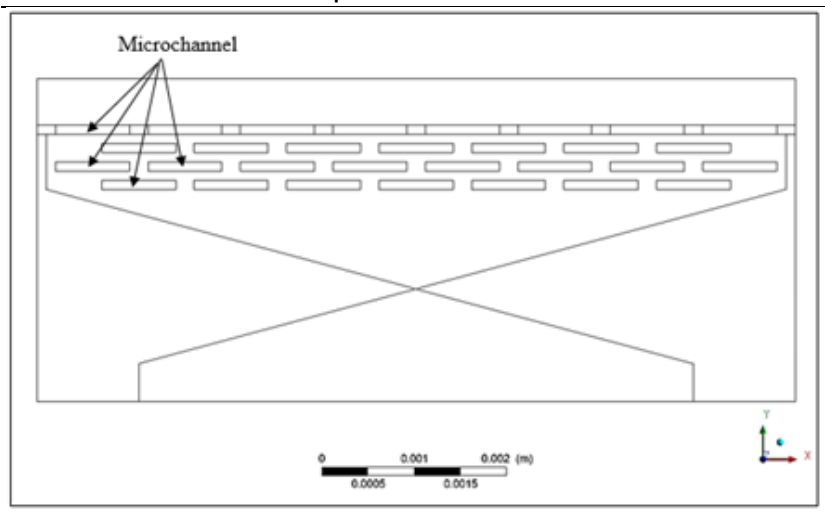

(b)

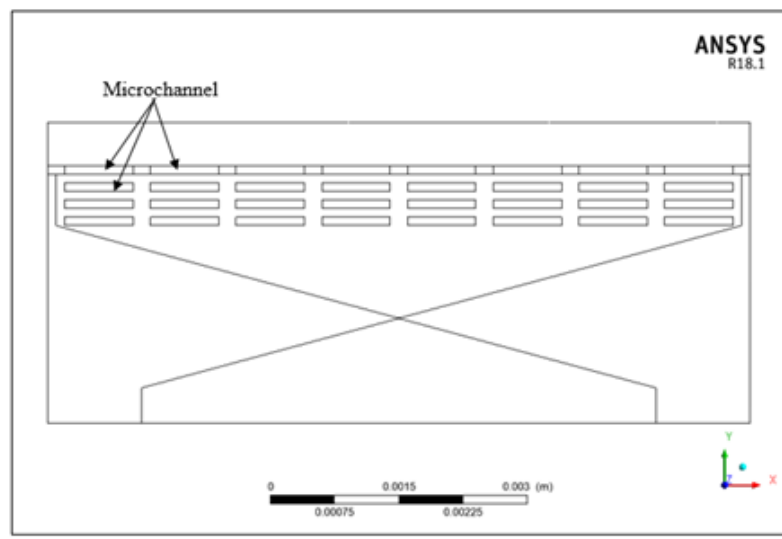

(a)

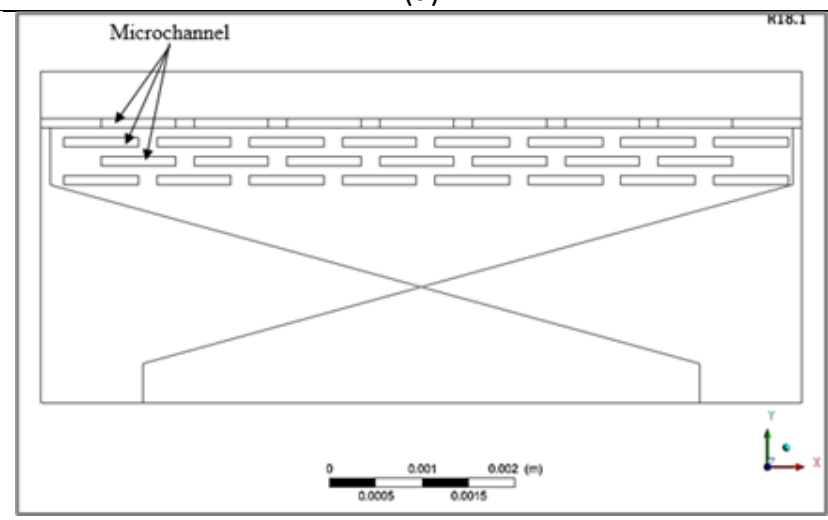

(c)

Fig. 1. Design of different simulation model (a) Model 1, (b) Model 2 and (c) Model 3 

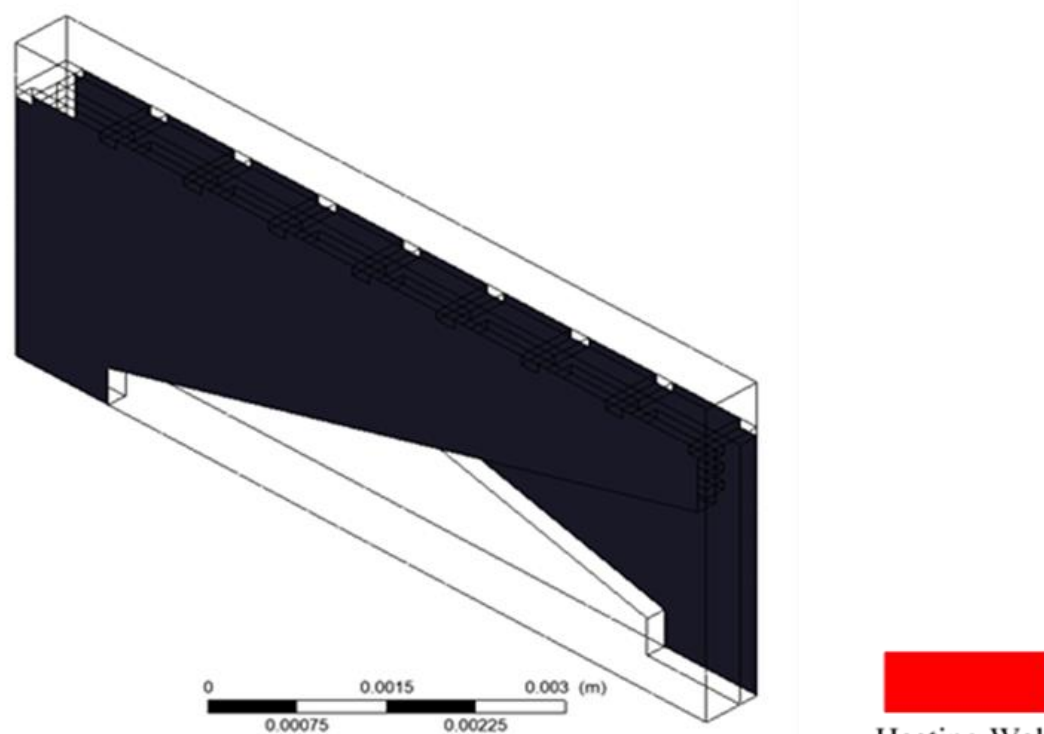

Heating Wall

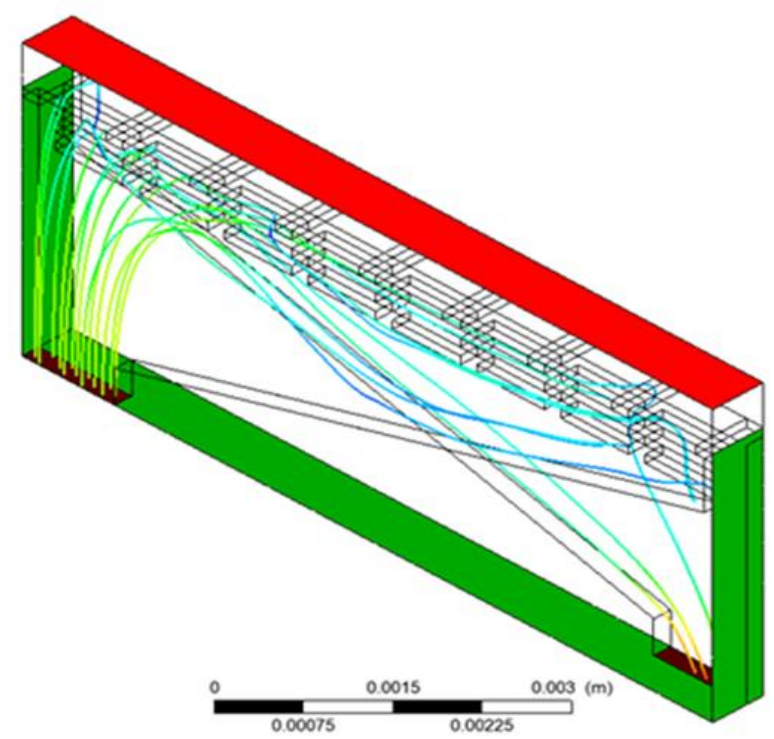

Insulated Wall

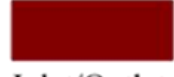

Inlet/Outlet

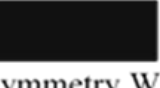

Symmetry Wal

Fig. 2. Example of boundary condition set up

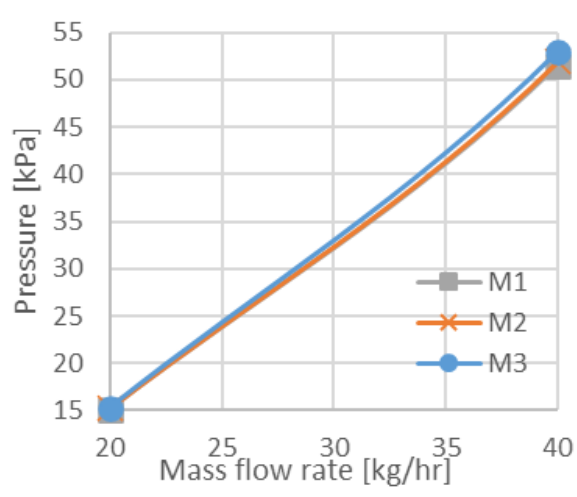

(a)

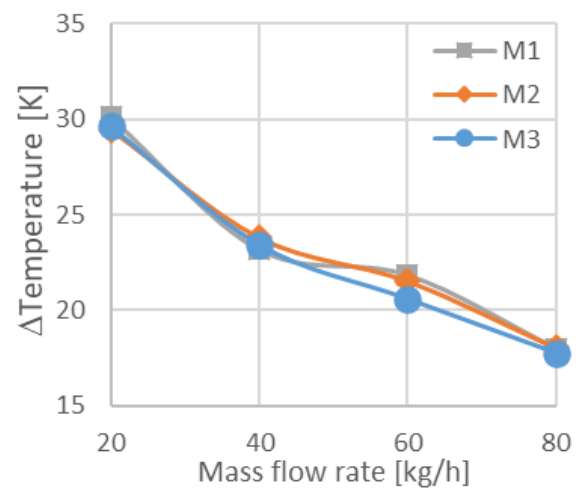

(b)

Fig. 3. Grid independent test result for (a) Pressure drop (b) Temperature difference 


\section{Results}

Results for this simulation study is divided into three different sections. The first section is the validation of simulation with previous research. Then, the temperature and flow visualization and the last section is comparison of thermal hydraulic performance.

\subsection{Comparison of Friction Factor}

The effect of multilayer channel arrangement is compared with single layer results [1,3] and theoretical calculation introduced by previous researchers $[14,15]$. Figure 4 shows the results of apparent friction factor vs the Reynolds number. The result shows that multilayer channel improves the flow movement and reduced the pressure drop. Therefore, reduced the apparent friction factor of the device. However, the reduction of apparent friction factor is more significant for a lower Reynolds number compared to a higher one.

\subsection{Temperature and Flow Visualization}

Figure 5 shows the result for temperature distribution along the microchannel with the heat flux of $400 \mathrm{~W} / \mathrm{cm}^{2}$ imposed to the heating block and the water mass flow rate of $40 \mathrm{~kg} / \mathrm{h}$. Model 2 recorded better heat transfer performance by creating less heating spot compared to Model 3 and Model 1. Model 1 shows the highest temperature of hot spot compared to the others. The hot spot occurred in this kind of arrangement due to the flow maldistribution through the channels. The affected channels could be seen clearly in Figure 6 . The hot spot was formatted as the results of stagnant point at the inlet of the distribution channels as shown in Figure 7. The effect of distribution channel design to the flow uniformity has been discussed by many researchers previously [16-18]. However, by varying the microchannel arrangement, this disadvantage could be minimized.

\subsection{Comparison of Thermal Hydraulic Performance}

Figure 8 shows the pressure drop and temperature difference between the inlet and heating surface versus the mass flow rate for all three models. From the results, Model 3 has the lowest pressure drop compared to the other design. Even though the total number of microchannels is almost the same for all models, the flow uniformity reduces the pressure drop significantly. Comparing the heat transfer performance of all models, it is cleared that Model 2 and Model 3 is better by $8 \%$ than Model 1 especially for a higher mass flow. Even though Model 1 has more surface transferring heat based on number of channels, the water flows into the microchannels in Model 1 is not evenly distributed which caused the lower heat transfer rate compared to the other two models. 


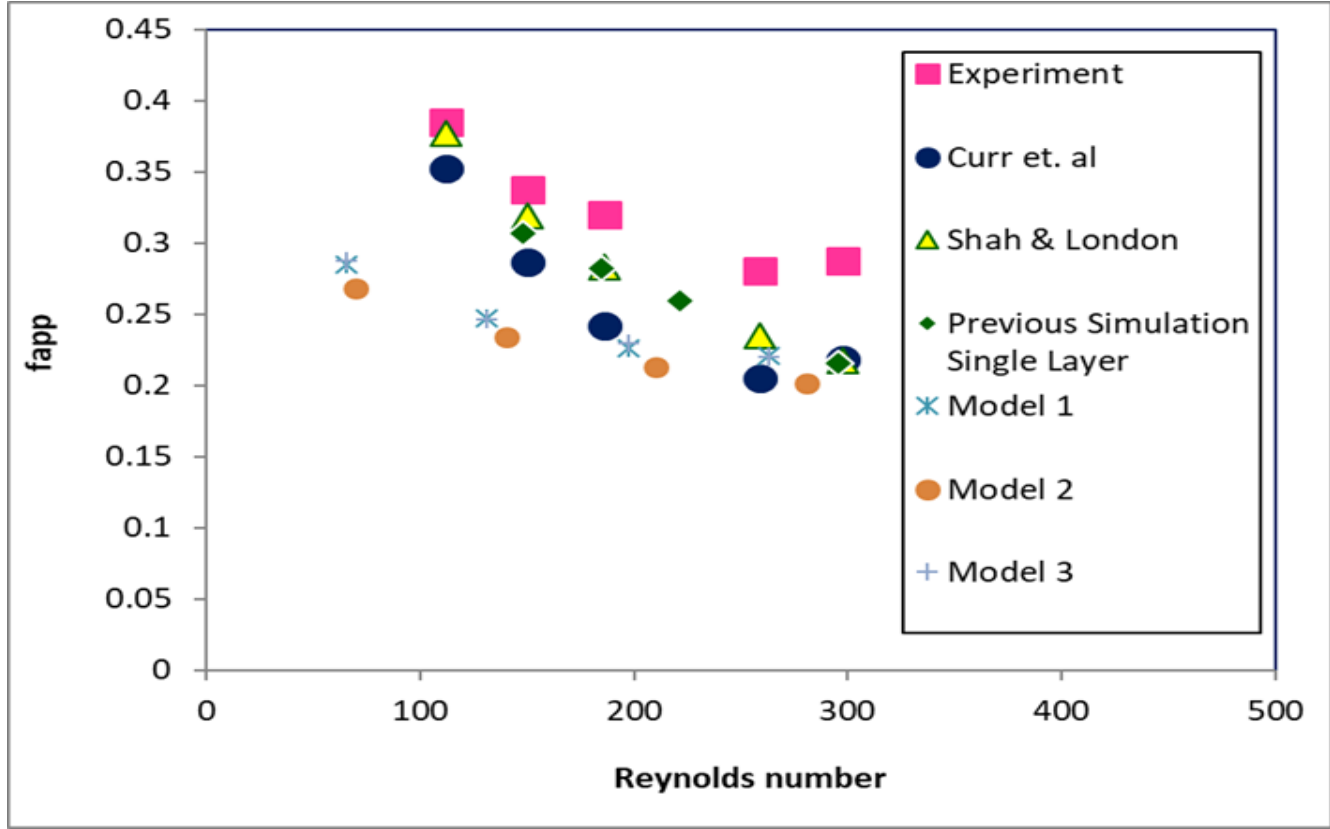

Fig. 4. Comparison of friction factor between models and single layer channel
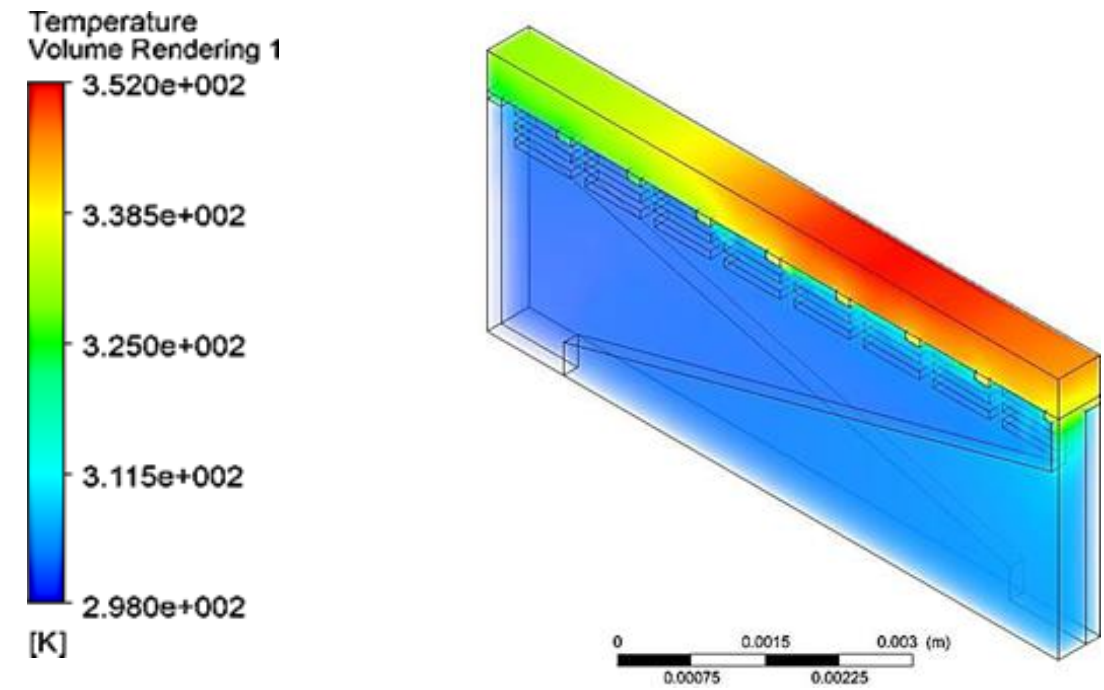

(a)

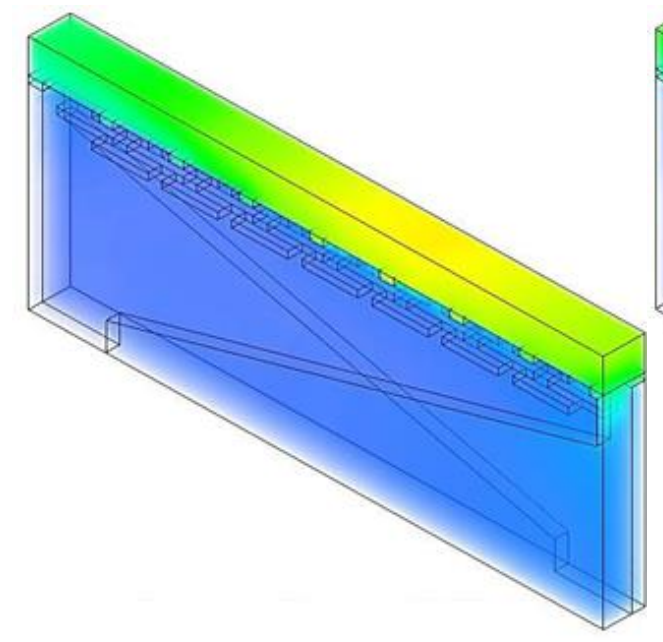

(b)

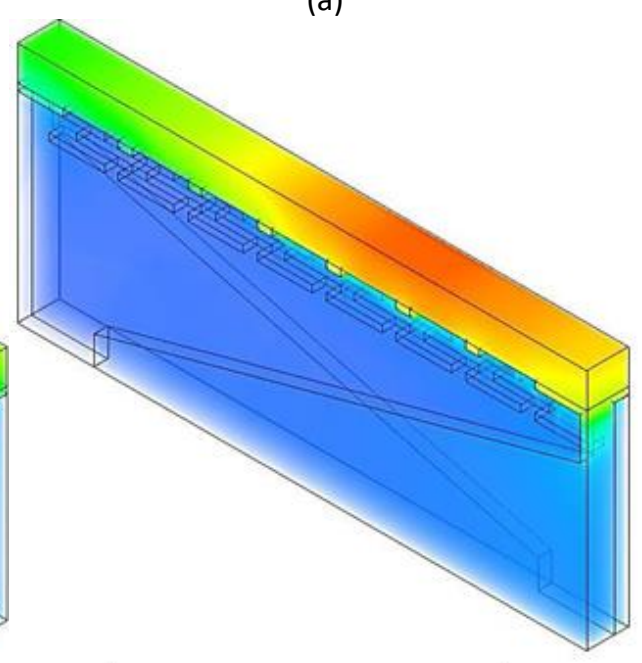

(c)

Fig. 5. Temperature distribution for (a) Model 1, (b) Model 2 and (c) Model 3 


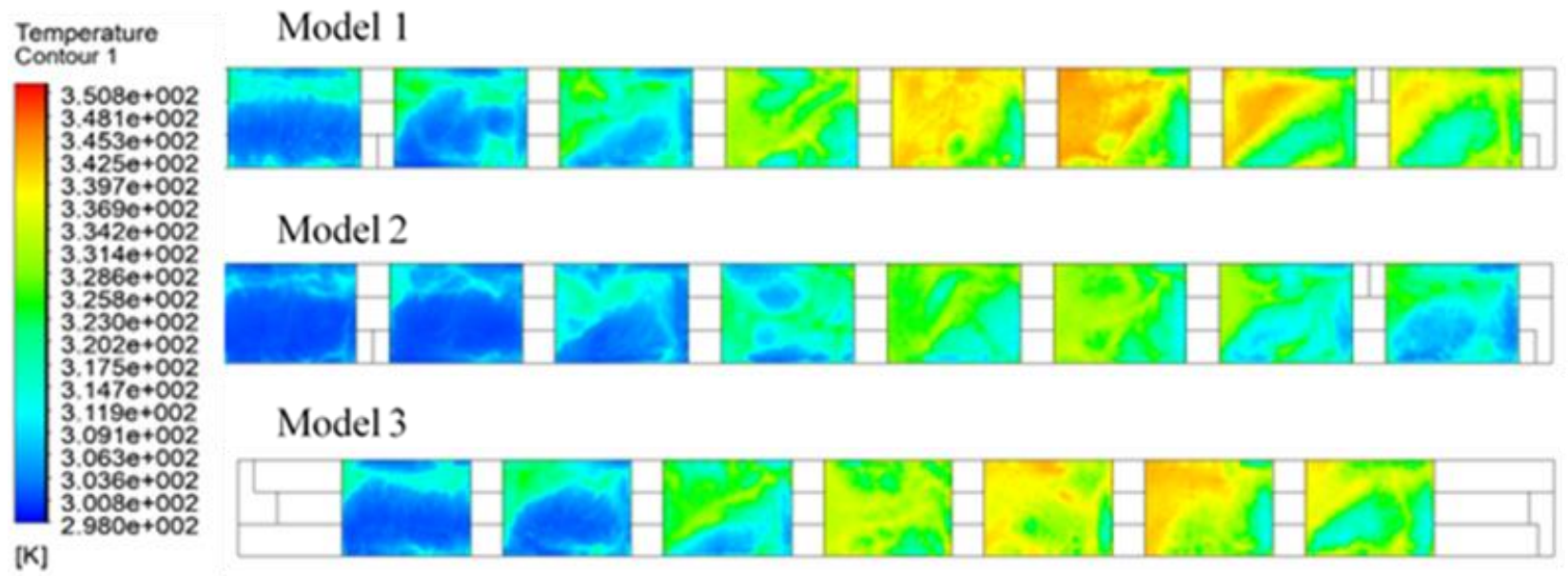

Fig. 6. Temperature distribution at the surface that contact with heating block

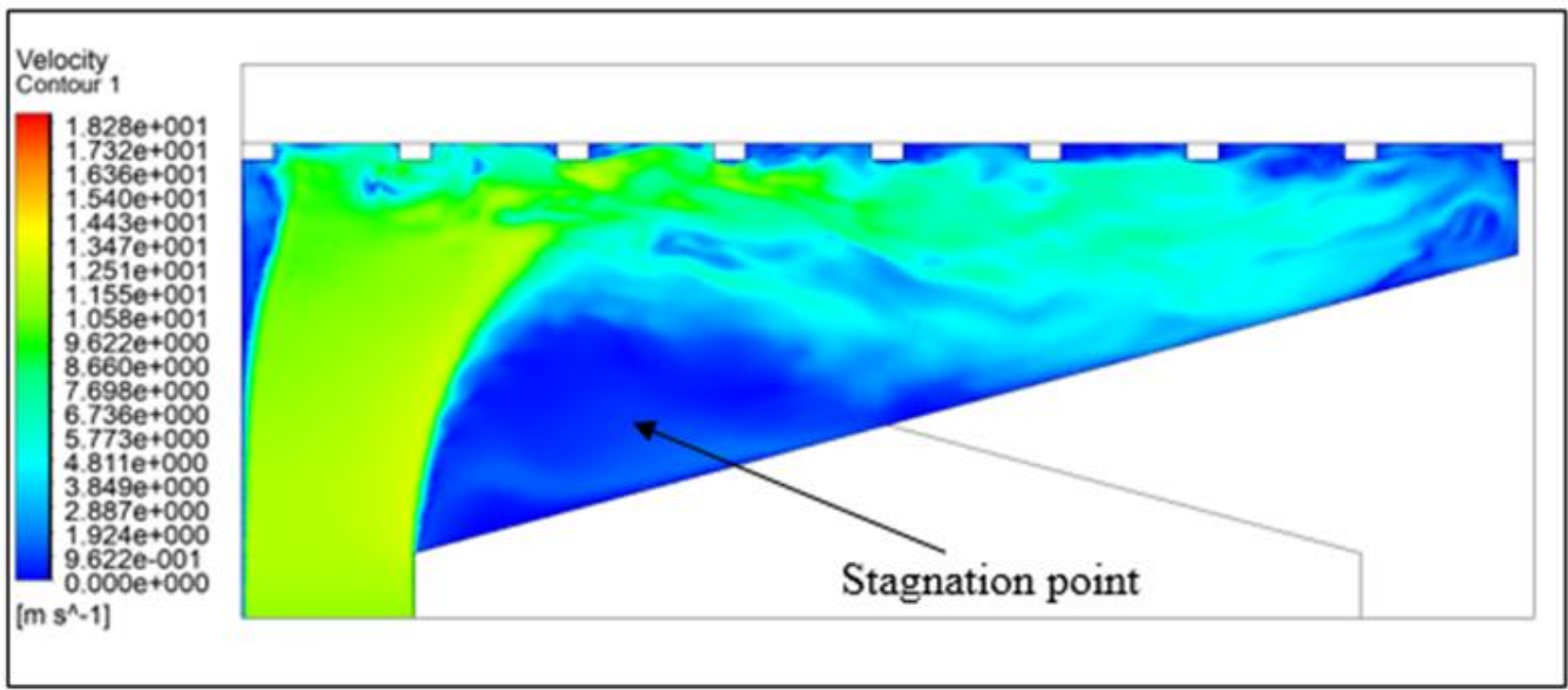

Fig. 7. Velocity profile at the outlet distribution channel

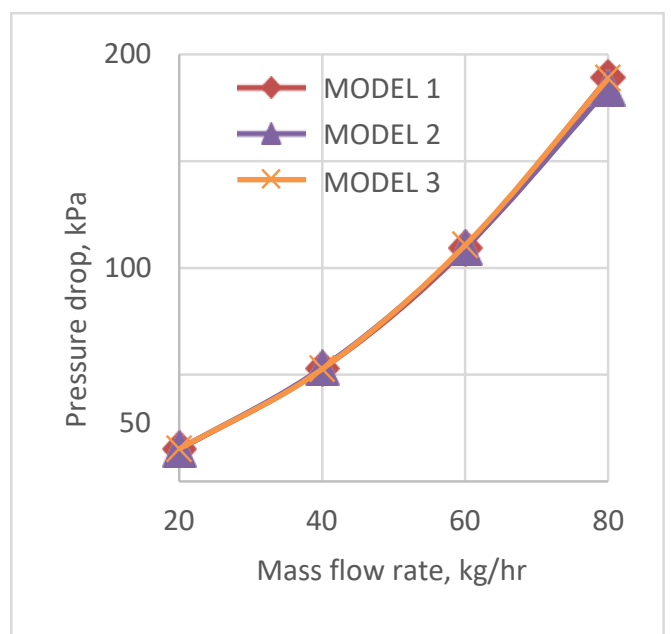

(a)

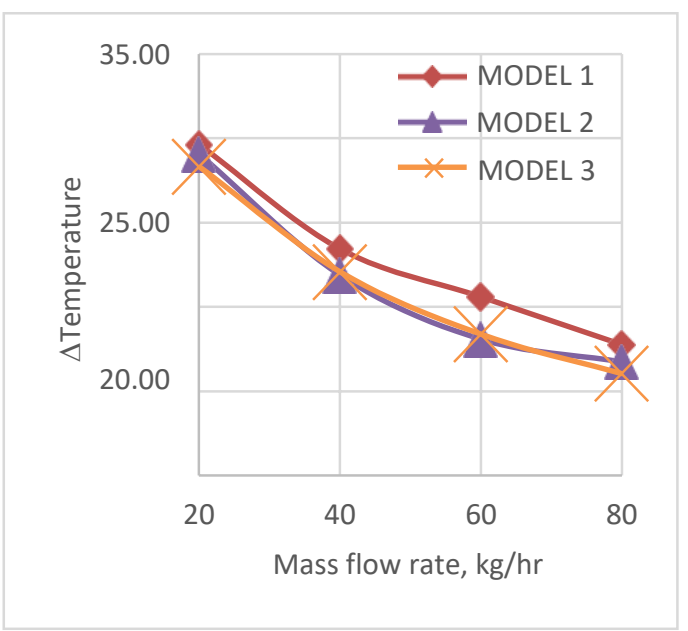

(b)

Fig. 8. (a) Comparison of pressure drop for different model, (b) Temperature difference between the inlet and heating surface for each model 


\section{Conclusions}

Investigation of the effect of multilayer channel arrangement on the thermal hydraulic performance of microchannel devices has been performed. The results show that an arrangement of eight-seven-eight-seven microchannels in four layers come out as the best arrangement in current study. This arrangement allowed the water to flow in each microchannels with almost similar velocity. Therefore, the heat transfer is transferred smoothly and preventing the hot spot formation on certain area. Further study should be performed experimentally, to look at the performance of this arrangement in actual devices.

\section{Acknowledgement}

This research was funded by a UTM Transdisciplinary Research Grant from Universiti Teknologi Malaysia (PY/2018/03302).

\section{References}

[1] Kamaruzaman, Natrah Binti, Flavio Brighenti, Juergen J. Brandner, and Aminuddin Saat. "Prediction of micro surface cooler performance for different rectangular type microchannels dimensions." International journal of heat and fluid flow 44 (2013): 644-651.

https://doi.org/10.1016/i.ijheatfluidflow.2013.09.005

[2] Li, Zhuo, Ya-Ling He, Gui-Hua Tang, and Wen-Quan Tao. "Experimental and numerical studies of liquid flow and heat transfer in microtubes." International Journal of Heat and Mass Transfer 50, no. 17-18 (2007): 3447-3460.

https://doi.org/10.1016/i.ijheatmasstransfer.2007.01.016

[3] Brighenti, Flavio, Natrah Kamaruzaman, and Juergen J. Brandner. "Investigation of self-similar heat sinks for liquid cooled electronics." Applied thermal engineering 59, no. 1-2 (2013): 725-732.

https://doi.org/10.1016/i.applthermaleng.2013.01.001

[4] Wong, Wai Hing, and Normah Mohd Ghazali. "Numerical simulation of a microchannel for microelectronic cooling." Jurnal Teknologi 46, no. 1 (2007): 1-16.

https://doi.org/10.11113/jt.v46.278

[5] Tikadar, Amitav, Saad K. Oudah, Titan C. Paul, Azzam S. Salman, A. K. M. M. Morshed, and Jamil A. Khan. "Parametric study on thermal and hydraulic characteristics of inter-connected parallel and counter flow mini-channel heat sink." Applied Thermal Engineering 153 (2019): 15-28.

https://doi.org/10.1016/i.applthermaleng.2019.02.007

[6] Ghani, Ihsan Ali, Natrah Kamaruzaman, and Nor Azwadi Che Sidik. "Heat transfer augmentation in a microchannel heat sink with sinusoidal cavities and rectangular ribs." International Journal of Heat and Mass Transfer 108 (2017): 1969-1981. https://doi.org/10.1016/j.ijheatmasstransfer.2017.01.046

[7] Ghani, Ihsan Ali, Nor Azwadi Che Sidik, and Natrah Kamaruzaman. "Hydrothermal performance of microchannel heat sink: The effect of channel design." International Journal of Heat and Mass Transfer 107 (2017): 21-44. https://doi.org/10.1016/i.ijheatmasstransfer.2016.11.031

[8] Herwig, H. "Flow and heat transfer in micro systems: Is everything different or just smaller?." ZAMM-Journal of Applied Mathematics and Mechanics/Zeitschrift für Angewandte Mathematik und Mechanik: Applied Mathematics and Mechanics 82, no. 9 (2002): 579-586.

[9] Alawi, Omer A., Nor Azwadi Che Sidik, H. A. Mohammed, and S. Syahrullail. "Fluid flow and heat transfer characteristics of nanofluids in heat pipes: a review." International Communications in Heat and Mass Transfer 56 (2014): 50-62.

https://doi.org/10.1016/j.icheatmasstransfer.2014.04.014

[10] Morshed, A. K. M. M., and Jamil A. Khan. "Numerical analysis of single phase multi layered micro-channel heat sink with inter-connects between vertical channels." In International Heat Transfer Conference, vol. 49415, pp. 133-140. 2010.

https://doi.org/10.1115/lHTC14-22828

[11] Zhai, Yuling, Zhouhang Li, Hua Wang, and Jianxin Xu. "Thermodynamic analysis of the effect of channel geometry on heat transfer in double-layered microchannel heat sinks." Energy Conversion and Management 143 (2017): 431 439.

https://doi.org/10.1115/IHTC14-22828 
[12] Nadaraja, Darvind, Natrah Kamaruzaman, Ummikalsom Abidin, and M. Mohd Sies. "Experimental study on the effect of multilayer microchannel arrangement to the thermal hydraulic performance of microchannel arrays." Journal of Advanced Research in Fluid Mechanics and Thermal Sciences 57, no. 1 (2019): 23-31.

[13] Xie, Gongnan, Yanquan Liu, Bengt Sunden, and Weihong Zhang. "Computational study and optimization of laminar heat transfer and pressure loss of double-layer microchannels for chip liquid cooling." Journal of Thermal Science and Engineering Applications 5, no. 1 (2013). https://doi.org/10.1115/1.4007778

[14] Shah, Ramesh K., and Alexander Louis London. Laminar flow forced convection in ducts: a source book for compact heat exchanger analytical data. Academic press, 2014.

[15] Curr, R. M., Devraj Sharma, and D. G. Tatchell. "Numerical predictions of some three-dimensional boundary layers in ducts." Computer Methods in Applied Mechanics and Engineering 1, no. 2 (1972): 143-158. https://doi.org/10.1016/0045-7825(72)90001-1

[16] Tang, Wei, Licheng Sun, Hongtao Liu, Guo Xie, Zhengyu Mo, and Jiguo Tang. "Improvement of flow distribution and heat transfer performance of a self-similarity heat sink with a modification to its structure." Applied Thermal Engineering 121 (2017): 163-171.

https://doi.org/10.1016/j.applthermaleng.2017.04.051

[17] Commenge, J. M., L. Falk, J. P. Corriou, and M. Matlosz. "Optimal design for flow uniformity in microchannel reactors." AIChE journal 48, no. 2 (2002): 345-358.

https://doi.org/10.1002/aic.690480218

[18] Ghani, Ihsan Ali, Nor Azwadi Che Sidik, Natrah Kamaruzzaman, Wira Jazair Yahya, and Omid Mahian. "The effect of manifold zone parameters on hydrothermal performance of micro-channel HeatSink: A review." International Journal of Heat and Mass Transfer 109 (2017): 1143-1161. https://doi.org/10.1016/i.ijheatmasstransfer.2017.03.007 